\title{
Research on the Impact of Housing Price Volatility on Foreign Capital Entry from the Perspective of Spatial Spillover*
}

\author{
Likui $\operatorname{Lin}^{1}$ Xiumei $\mathrm{Li}^{1}$ Danqi $\mathrm{Li}^{2, * *}$ \\ ${ }^{1}$ School of Finance \& Investment, Guangdong University of Finance, Guangzhou, Guangdong 510521, China \\ ${ }^{2}$ School of Economics \& Trade, Guangzhou Xinhua University, Guangzhou, Guangdong 510520, China \\ ${ }^{* *}$ Corresponding author. Email: lidanqiedu@163.com
}

\begin{abstract}
Foreign direct investment in the local market is an indispensable driving force for China to accelerate the new development pattern of Chinese and international dual circulation. The continuous increase in the sale price of commercial housing in China will inevitably have an impact on the daily operations of foreign-funded enterprises. A more comprehensive understanding of the impact of housing price volatility on the entry of foreign capital from the perspective of spatial spillover will help the government to formulate more targeted regulatory policies. According to research results, it is found that the direct impact of volatility in local housing price on the entry of local foreign investment is not significant, but the indirect spillover effect on the entry of foreign capital in neighboring regions is significantly positive. In addition, measures such as expanding the capacity of the local market and increasing the total supply of local labor are all conducive to increasing the attractiveness of foreign investment.
\end{abstract}

Keywords: Housing price volatility, The entry of foreign capital, Spatial spillover, Spatial autocorrelation, Spatial Dubin Model.

\section{INTRODUCTION AND LITERATURE REVIEW}

The gradual formation of a new development pattern with the Chinese general circulation as the main body and the Chinese and international dual circulation promoting each other is an important development strategy for China in the coming period. Foreign-funded enterprises are indispensable market players in China's economy, and foreign direct investment will play an important role in China's "dual circulation" construction. Even in 2020, when COVID-19 epidemic was raging worldwide, the total foreign direct investment in China still achieved a growth rate of $6.2 \%$. Foreign

*Funds: Guangzhou Philosophy and Social Sciences Planning 2021 Project (Project Number: 2021GZGJ21); Guangdong Provincial Financial Scientific Research Project (Project Number: Z2021105); Innovative team project of ordinary colleges and universities in Guangdong Province (Project Number: 2018WCXTD004).

JEL classification code: F21, R31, R38; CLC Number: F114.4 enterprises entering the Chinese market bear the brunt of their operating costs, and the impact of commercial housing sale price on them cannot be ignored. In particular, the price of commercial housing in China has risen sharply recently, and the impact of housing price will be more prominent. Studying the effect of housing price volatility on the entry of foreign capital, formulating relevant policies accordingly, eliminating the adverse effects of housing price volatility on the entry of foreign capital, and continuing to escort the rooted development of foreign capital in China will be the objective requirements for accelerating the promotion of China's new development pattern.

Regarding the research on the impact of housing price volatility on foreign direct investment, most of the existing research results focus on the aspects of distribution of wealth and income triggered by changes in the sale price of commercial housing (Zezza, 2008) [1], labor force population mobility (Rabe and Taylor, 2012) [2], enterprise output (Zhou et al., 2020) [3], investment expenditure 
(Chaney, 2012) [4] and so on, indirectly deducing the impact of housing price volatility on foreign direct investment. However, among the current research results that can be retrieved, research results are still relatively rare, and research results that take the influence factor of spatial spillover into account are even rarer. Since the important role played by the factor of spatial spillover in the process of housing price volatility has been confirmed by a large number of research studies, under the circumstance that there may be spatial spillover effect in the mechanism by which commercial housing sale price volatility affects foreign direct investment, empirical research that ignores spatial spillover effect not only fails to more comprehensively reveal the objective law of the impact of housing price volatility; moreover, due to the error of the regression estimation, the erroneous understanding of the real economy will make the proposed policy suggestion unable to effectively solve the real problems faced by China's foreign investment.

Therefore, this article will introduce the spatial matrix of geographic distance, using global Geary's $c$ index (Geary, 1954) [5] and local Moran's I index (Anselin, 1995) [6] and other research tools to explore the possible spatial correlation between housing price volatility and foreign investment. In addition, it further introduces the Spatial Dubin Model considering the lagged variable to discuss the direct effect of local housing price volatility on the entry of local foreign capital and the spillover effect on the entry of foreign capital in neighboring regions, in order to better reveal the impact mechanism of housing price volatility on the entry of foreign capital from the perspective of spatial spillover.

\section{THE SPATIAL CORRELATION TEST BETWEEN HOUSING PRICE VOLATILITY AND FOREIGN CAPITAL ENTRY}

In this article, 31 provincial administrative regions in Chinese mainland are used as spatial units, and the geographic distance weight matrix $\mathrm{W} 1$ is set by the reciprocal of the geographic distance between the centroid points of each provincial administrative region. When the two places are adjacent, the value is the reciprocal of the geographic distance between the two centroid points; when the two places are not adjacent, the value is 0 . At the same time, it further uses the square of the reciprocal of the geographic distance between the centroid points of each provincial administrative region to set up a new geographic distance weight matrix W2 for robustness test.

Before constructing a spatial econometric model, it is necessary to explore the possible spatial correlation effect between housing price volatility and foreign capital entry. This article uses the deflated commercial housing sale price $\ln R L P$ and the deflated total foreign direct investment $\ln R L F D I$ as the observation value. The global Geary's $c$ index is used for the global spatiality test, and the local Moran's I index is used for the local spatiality test.

The deflated commercial housing sale price $\ln R L P$ and the deflated total foreign direct investment $\ln R L F D I$ 's global Geary's $c$ index calculation results of each provincial administrative region in Chinese mainland are shown in "Table 1". Taking into account the calculation results of the geographical distance weight matrix W1, the global Geary's $c$ index for the sale price of commercial housing and total foreign direct investment in each provincial administrative region of Chinese mainland from 2007 to 2019 passes the significance test. This shows that the autocorrelation between housing price volatility and foreign capital entry is significant in terms of spatial clustering in the global scope. Considering that the calculation results of the geographical distance weight matrix W2 are also consistent, this shows that the above calculation results pass the robustness test. 
Table 1. The global Geary's $c$ index of $\ln R L P$ and $\ln R L F D I$ from 2007 to 2019

\begin{tabular}{|c|c|c|c|c|}
\hline \multirow{2}{*}{ Year } & \multicolumn{2}{|l|}{$\ln R L P$} & \multicolumn{2}{|l|}{$\ln R L F D I$} \\
\hline & W1 & W2 & W1 & W2 \\
\hline \multirow{2}{*}{2007} & $0.508^{\star * *}$ & $0.514^{* * *}$ & $0.337^{* * *}$ & $0.329^{* \star *}$ \\
\hline & $(-3.276)$ & $(-3.118)$ & $(-4.565)$ & $(-4.428)$ \\
\hline \multirow{2}{*}{2008} & $0.518^{\star * *}$ & $0.519^{\star \star *}$ & $0.386^{\star * *}$ & $0.380^{\text {*** }}$ \\
\hline & $(-3.214)$ & $(-3.091)$ & $(-4.212)$ & $(-4.085)$ \\
\hline \multirow{2}{*}{2009} & $0.686^{* * *}$ & $0.716^{*}$ & $0.380^{* * *}$ & $0.374^{\star \star *}$ \\
\hline & $(-2.050)$ & $(-1.795)$ & $(-4.262)$ & $(-4.127)$ \\
\hline \multirow{2}{*}{2010} & $0.433^{* * *}$ & $0.437^{\star * *}$ & $0.427^{* * *}$ & $0.421^{\text {***}}$ \\
\hline & $(-3.783)$ & $(-3.622)$ & $(-3.912)$ & $(-3.794)$ \\
\hline \multirow{2}{*}{2011} & $0.413^{* * *}$ & $0.416^{\star \star *}$ & $0.430^{\star * *}$ & $0.425^{\star * *}$ \\
\hline & $(-3.953)$ & $(-3.786)$ & $(-3.907)$ & $(-3.785)$ \\
\hline \multirow{2}{*}{2012} & $0.423^{* \star *}$ & $0.430^{* \star *}$ & $0.419^{\star * *}$ & $0.413^{* \star *}$ \\
\hline & $(-3.869)$ & $(-3.681)$ & $(-3.997)$ & $(-3.878)$ \\
\hline \multirow{2}{*}{2013} & $0.428^{\star \star \star}$ & $0.440^{\star * *}$ & $0.397^{* * *}$ & $0.387^{\star \star *}$ \\
\hline & $(-3.809)$ & $(-3.599)$ & $(-4.159)$ & $(-4.049)$ \\
\hline \multirow{2}{*}{2014} & $0.459^{* * *}$ & $0.477^{* * *}$ & $0.396^{* * *}$ & $0.386^{* * *}$ \\
\hline & $(-3.535)$ & $(-3.305)$ & $(-4.152)$ & $(-4.052)$ \\
\hline \multirow{2}{*}{2015} & $0.435^{\star * *}$ & $0.455^{\star \star *}$ & $0.390^{* * *}$ & $0.381^{* * *}$ \\
\hline & $(-3.679)$ & $(-3.437)$ & $(-4.218)$ & $(-4.098)$ \\
\hline \multirow{2}{*}{2016} & $0.402^{\star * *}$ & $0.418^{* * *}$ & $0.370^{* * *}$ & $0.361^{\text {***}}$ \\
\hline & $(-3.898)$ & $(-3.674)$ & $(-4.352)$ & $(-4.231)$ \\
\hline \multirow{2}{*}{2017} & $0.420^{\star \star * *}$ & $0.431^{\star * *}$ & $0.451^{* * *}$ & $0.445^{\star \star *}$ \\
\hline & $(-3.792)$ & $(-3.595)$ & $(-3.760)$ & $(-3.651)$ \\
\hline \multirow{2}{*}{2018} & $0.436^{* * *}$ & $0.446^{* \star *}$ & $0.460^{\star * *}$ & $0.449^{* * *}$ \\
\hline & $(-3.705)$ & $(-3.518)$ & $(-3.681)$ & $(-3.607)$ \\
\hline \multirow{2}{*}{2019} & $0.468^{* * *}$ & $0.480^{* * *}$ & $0.461^{* * *}$ & $0.447^{* * *}$ \\
\hline & $(-3.470)$ & $(-3.281)$ & $(-3.661)$ & $(-3.614)$ \\
\hline
\end{tabular}

Note: (1) The numerical values in parentheses are $\mathrm{z}$ statistics; (2) ***,** and * respectively indicate that the significance level is less than 1\%, less than 5\% and less than $10 \%$; (3) Matrix W1 refers to the geographical distance weight matrix calculated by using the reciprocal of the distance between two places; the matrix W2 refers to the geographical distance weight matrix calculated by the square of the reciprocal of the distance between the two places.

Next, it further calculates the local Moran's I index of the deflated commercial housing sale price $\ln R L P$ and the deflated total foreign direct investment $\ln R L F D I$. Taking into account the calculation results of the geographical distance weight matrix $\mathrm{W} 1$, the local spatial correlation characteristics of the sale price of commercial housing and the total foreign direct investment from 2007 to 2019 are quite different. The sale price of commercial housing in the eastern regions such as Beijing, Tianjin, Shanghai and Zhejiang presents significant "high-high" spatial agglomeration characteristics; the total amount of foreign direct investment in eastern regions such as Shanghai, Jiangsu and Zhejiang presents a significant "highhigh" spatial agglomeration, and presents a significant "low-low" spatial agglomeration characteristics in western regions such as Tibet, Gansu, Qinghai, Ningxia, and Xinjiang. Judging from "Figure 1" and "Figure 2", the observed values of most provincial administrative regions show obvious characteristics of "high-high" or "low-low" spatial agglomeration. Moreover, after comparing the characteristics of the two years, it can be found that the spatial agglomeration characteristics in 2019 are more obvious, which shows that the role of spatial geographic factors in the process of changes in China's commercial housing sale prices and foreign direct investment cannot be ignored. 

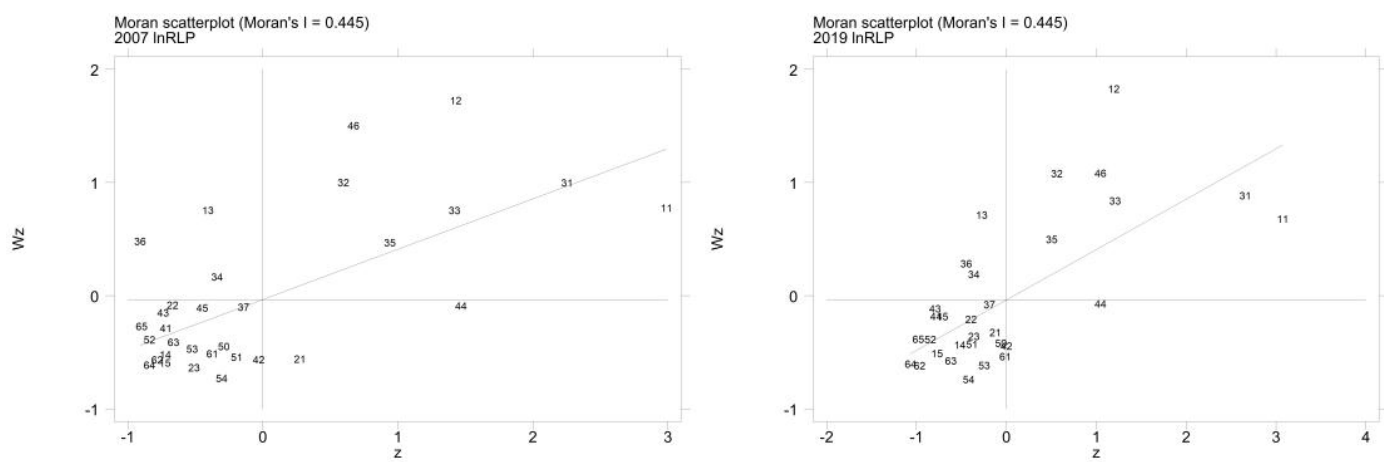

Figure 1 The scatter plot of local Moran's I index of commercial housing sale price in 2007 and 2019 (matrix W1).
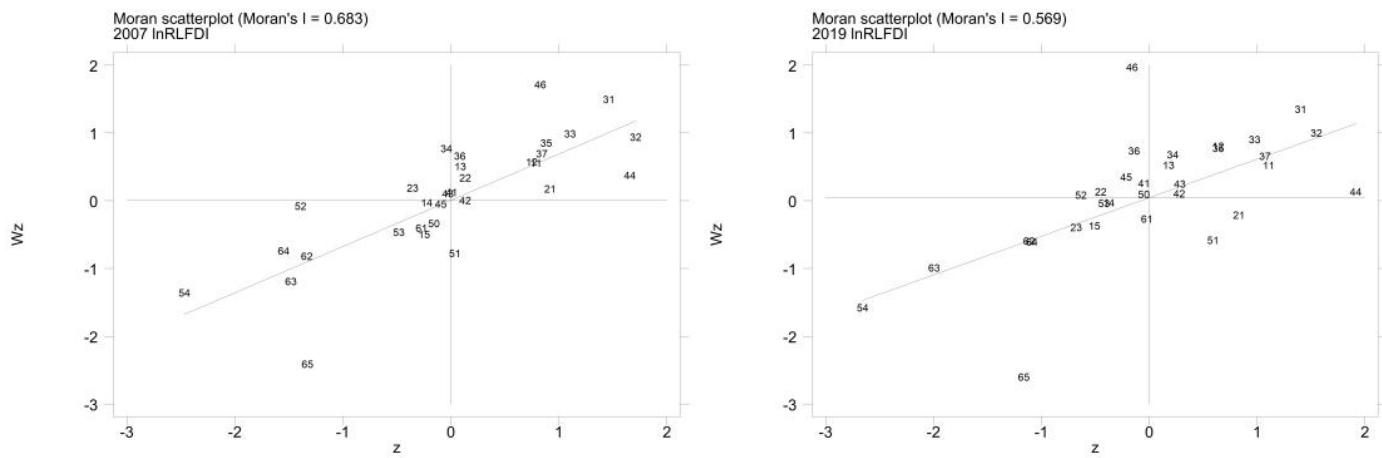

Figure 2 The scatter plot of local Moran's I index of the total foreign direct investment in 2007 and 2019 (matrix W1).

The calculation result of the geographical distance weight matrix W2 is basically consistent with the above conclusion. Therefore, spatial spillover is an important factor to be considered in the study of the impact of volatility in the sale price of commercial housing in a region on the entry of foreign capital. In the next step, this article will build a spatial econometric model to explore its internal mechanism of action.

\section{MODEL SETUP AND DATA SPECIFICATION}

\subsection{Setup of Spatial Econometric Model}

As mentioned above, this article will build a spatial econometric model to fully consider the influence of geospatial factors (Lee and $\mathrm{Yu}, 2010$ )
[7]. The LM test result using the geographical distance weight matrix W1 shows that the LMlag statistical significance level of the impact of the volatility of the sale price of commercial housing on foreign direct investment is less than $5 \%$ and the value is 4.013. The significance level of the LMerr statistic is less than $5 \%$ and the value is 2.236 , that is, the LMlag statistic is greater than the LMerr statistic, which shows that the spatial correlation of the spatial lagged dependent variable is dominant (Anselin, 1988) [8], and it is more reasonable to choose the Spatial Dubin Model at this time. The LM test result using the geographical distance weight matrix W2 is consistent with the above result, and the LM test result passes the robustness test. The specific form of the Spatial Dubin Model used in this article is shown in equation (1).

$\ln R L F D I_{i t}=\rho \sum_{j=1}^{n} W_{i j} \ln R L F D I_{j t}+\beta \ln R L P_{i, t-1}+\theta \sum_{j=1}^{n} W_{i j} \ln R L P_{j t}+\gamma \ln X_{i, t-1}+\kappa \sum_{j=1}^{n} W_{i j} \ln X_{j, t-1}+\mu_{i}+\lambda_{t}+\varepsilon_{i t}$

As shown in formula (1), $\rho$ is the spatial lagged regression coefficient and is not equal to $0 ; \theta$ is the space error regression coefficient and is not equal to $0 ; W$ is the spatial weight matrix, and $X$ is the control variable. The control variables used in this article include gross domestic product, per capita gross domestic product, and total trade export- import volume that measure the level of economic development, the employed population in urban work units at the end of the year as a measure of the level of factor endowment, and the proportion of urban population in total population at the end of the year and the number of higher education students per 100,000 people in school and turnover 
volume of freight traffic as a measure of the level of infrastructure. The significance level of the Hausman test of formula (1) is less than $1 \%$, which shows that the fixed effect model is more appropriate. Furthermore, the $L R$ test has a significance level of less than $1 \%$ and rejects the null hypothesis that the spatial lagged regression coefficient is equal to 0 and the spatial error regression coefficient is equal to 0 respectively. This once again proves that it is more appropriate to use the Spatial Dubin Model. Now, $\rho$ is used to measure the direct effect of the volatility of the sale price of local commercial housing on the total amount of local foreign direct investment. $\theta$ is used to measure the indirect spillover effect of volatility in the sale price of local commercial housing on the total amount of foreign direct investment in neighboring regions.

\subsection{Data Source and Variable Declaration}

The original data in this article comes from statistical data published by the National Bureau of Statistics of China. First of all, in order to eliminate the influence of inflation factors and deal with possible heteroscedasticity problems, the sale price level of commercial housing is deflated by the consumer price index and then its logarithm form is

Table 2. Variable indicator description and descriptive statistics

\begin{tabular}{|c|c|c|c|c|c|c|}
\hline Variable & Variable declaration & $\begin{array}{l}\text { Sample } \\
\text { size }\end{array}$ & $\begin{array}{l}\text { Mean } \\
\text { value }\end{array}$ & $\begin{array}{l}\text { Standard } \\
\text { deviation }\end{array}$ & Minimum & Maximum \\
\hline $\ln R L P$ & Commercial housing sale price & 403 & 8.4363 & 0.5072 & 7.5006 & 10.1973 \\
\hline $\ln R L F D I$ & Total foreign direct investment & 403 & 6.0337 & 1.5452 & 1.5538 & 9.6015 \\
\hline $\ln R L G D P$ & Gross domestic product & 403 & 9.3909 & 1.0601 & 5.8354 & 11.5464 \\
\hline $\ln R L P G D P$ & Per capita gross domestic product & 403 & 10.4904 & 0.5827 & 8.9292 & 12.0884 \\
\hline $\ln R L / E$ & Total foreign trade export-import volume & 403 & 7.4788 & 1.7363 & 2.723 & 10.956 \\
\hline $\ln W$ & $\begin{array}{l}\text { The employed population in urban work units } \\
\text { at the end of the year }\end{array}$ & 403 & 6.6281 & 0.9233 & 3.7195 & 8.8725 \\
\hline $\ln U N$ & $\begin{array}{l}\text { The proportion of urban population in total } \\
\text { population at the end of the year }\end{array}$ & 403 & 3.9601 & 0.2655 & 3.0681 & 4.4954 \\
\hline $\ln S T U$ & $\begin{array}{l}\text { The number of higher education students per } \\
100,000 \text { people in school }\end{array}$ & 403 & 7.7472 & 0.3404 & 6.8068 & 8.8285 \\
\hline $\ln C T$ & The turnover volume of freight traffic & 403 & 7.9471 & 1.1755 & 3.5650 & 10.3197 \\
\hline
\end{tabular}

\section{EMPIRICAL RESULTS AND ANALYSIS}

\subsection{Baseline Regression Results and Analysis}

Through Hausman test, it is determined that the two-way fixed effect form is used for panel used to obtain the variable $\ln R L P$, the total amount of foreign direct investment is deflated by the consumer price index and then its logarithm form is used to get the variable $\ln R L F D I$, the gross domestic product is deflated by the industrial producer price index and then its logarithm form is used to get the variable $\ln R L G D P$, the per capita gross domestic product is deflated by the industrial producer price index and then its logarithm form is taken to get the variable $\ln R L P G D P$, the employed population in urban work units at the end of the year is taken in logarithm to obtain the variable $\ln W$, the proportion of urban population in total population at the end of the year is taken in logarithm to get the variable $\ln U N$, the number of higher education students per 100,000 people in school is taken in logarithm to get the variable $\ln S T U$, and the turnover volume of freight traffic is taken in logarithm to obtain the variable $\ln C T$. Secondly, in order to deal with possible endogenous problems, this article selects the firstorder lagged variable of the core explanatory variable and the first-order lagged variable of the control variable as instrumental variables to participate in the regression. The descriptive statistical analysis results of all variables after treatment are shown in "Table 2 ". 
local housing price volatility on the inflow of foreign capital in neighboring regions is significant positive and is equal to 0.268 , showing that the volatility in housing price has spatial spillover effect on changes in total foreign direct investment. (3) From the results of local direct effect, although the regression coefficient that measures the impact of local housing price volatility on the entry of local foreign capital is positive, it fails to pass the significance test. In other words, on the basis of controlling other variables that affect the total amount of foreign direct investment, the effect of housing price volatility on the entry of local foreign investment is not statistically significant. (4) From the perspective of indirect spillover effect in neighboring regions, the regression coefficient that measures the impact of local housing price volatility on the inflow of foreign capital in neighboring regions passes the significance test and is a regression coefficient greater than the local direct effect. This shows that on the basis of controlling other variables that affect the total amount of foreign direct investment, the impact of local housing price volatility on foreign investment is mainly manifested in the spillover effect on neighboring regions, that is to say, the increase in local housing price not only does not help local foreign investment, but may also cause local foreign-funded enterprises to relocate to neighboring regions.

Table 3. Panel regression results using matrix W1 weighting

\begin{tabular}{|c|c|c|}
\hline & \multicolumn{2}{|l|}{$\ln R L F D I$} \\
\hline & Local direct effect & Indirect spillover effect \\
\hline \multirow{2}{*}{$\ln R L P$} & 0.006 & $0.261^{*}$ \\
\hline & $(0.083)$ & $(0.138)$ \\
\hline \multirow{2}{*}{$\ln R L G D P$} & $2.301^{* * *}$ & -0.725 \\
\hline & $(0.491)$ & $(0.791)$ \\
\hline \multirow{2}{*}{ In $R L P G D P$} & $-2.308^{* * *}$ & 0.193 \\
\hline & $(0.553)$ & $(0.881)$ \\
\hline \multirow{2}{*}{$\ln R L I E$} & $-0.113^{\star *}$ & 0.023 \\
\hline & $(0.045)$ & $(0.056)$ \\
\hline \multirow{2}{*}{$\ln W$} & $0.301^{* *}$ & 0.105 \\
\hline & $(0.121)$ & $(0.130)$ \\
\hline \multirow{2}{*}{$\ln U N$} & $1.546^{* * *}$ & $3.316^{* * *}$ \\
\hline & $(0.433)$ & $(0.806)$ \\
\hline \multirow{2}{*}{$\ln S T U$} & 0.115 & 0.214 \\
\hline & $(0.197)$ & $(0.374)$ \\
\hline \multirow{2}{*}{$\ln C T$} & $-0.109^{* *}$ & $-0.345^{* * *}$ \\
\hline & $(0.044)$ & $(0.072)$ \\
\hline \multirow{2}{*}{$\mathrm{W}^{*} \ln R L P$} & $0.268^{*}$ & \\
\hline & $(0.146)$ & \\
\hline rho & 0.042 & \\
\hline$R^{2}$ & 0.784 & \\
\hline $\log L$ & 22.342 & \\
\hline Sigma² & $0.052^{\star * *}$ & \\
\hline Observed value & 372 & \\
\hline
\end{tabular}

a Note: The standard error term of the regression coefficient is in parentheses; ***,** and * indicate that the significance level is less than $1 \%$, less than $5 \%$, and less than $10 \%$, respectively.

The reasons for the above results may be: (1) The increase in the sale price of local commercial housing may cause an increase in the operating cost of local foreign-funded enterprises in the short term, but at the same time, the wealth income effect of rising housing price may also lead to an increase in the local government's fiscal revenue. The local government can provide more preferential policies for local foreign-funded enterprises through transfer payment, so as to minimize the adverse impact of housing price volatility on the operating cost of enterprises. Therefore, in a statistical sense, it shows that the impact of housing price volatility on the entry of local foreign capital is not significant. (2) But in the meantime, when the sale price of local commercial housing rises, in addition to 
seeking local government's transfer payment to offset the amount of increase in operating cost, local foreign-funded enterprises can also avoid the adverse impact of rising local housing price by relocating to neighboring regions with lower housing price. When the earning of enterprise relocation is greater than the cost of enterprise relocation, foreign-funded enterprises may adopt capacity spillover strategies against neighboring regions. At this time, in a statistical sense, it shows that the spatial spillover effect of local housing price volatility on the inflow of foreign capital in neighboring regions is significantly positive.

From the point of view of the control variables: (1) The effect of gross domestic product on the entry of local foreign capital is significantly positive, which shows that the capacity of the local market has been expanded, which is conducive to attracting foreign direct investment; (2) The effect of per capita gross domestic product on the entry of local foreign investment is significantly negative. This may be because part of the reason for foreign direct investment in China is to pursue cheaper labor cost input, and the increase in per capita labor productivity may lead to an increase in labor cost as well, thus affecting the incentive for foreign direct investment in China; (3) The total foreign trade export-import volume has a significant negative impact on the entry of local foreign investment, which indicates that local enterprises may capture the market share of foreign-funded enterprises by developing international trade market; (4) The employed population in urban work units has a significant positive effect on the entry of local foreign investment, which once again proves that part of the reason for foreign direct investment in China is to pursue lower labor cost input; (5) The level of urbanization has a significant positive effect on the entry of local foreign capital, which shows that the development of urbanization will create more market capacity for enterprises and help attract foreign direct investment; (6) The effect of the turnover volume of freight traffic on the entry of local foreign capital is significantly negative. This shows that with the improvement of the external transportation level, even if foreignfunded enterprises don't participate in the local production and operation activities, their products can also enter the local market through logistics, which to a certain extent inhibits the enthusiasm of foreign capital to enter the local area to carry out direct investment.

\subsection{Robustness Test}

Next, the matrix W2 is further used for robustness test. Through Hausman test, it is determined that the two-way fixed effect form is used for panel regression. The regression results are shown in "Table 4". The results are basically consistent with "Table 3", and the regression results of "Table 3" pass the robustness test. 
Table 4. Panel regression results using matrix W2 weighting

\begin{tabular}{|c|c|c|}
\hline & \multicolumn{2}{|l|}{$\ln R L F D I$} \\
\hline & Local direct effect & Indirect spillover effect \\
\hline \multirow{2}{*}{$\ln R L P$} & -0.010 & $0.197^{*}$ \\
\hline & $(0.083)$ & $(0.115)$ \\
\hline \multirow{2}{*}{$\ln R L G D P$} & $2.452^{* \star *}$ & -0.606 \\
\hline & $(0.503)$ & $(0.508)$ \\
\hline \multirow{2}{*}{$\ln R L P G D P$} & $-2.650^{\star * *}$ & 0.282 \\
\hline & $(0.555)$ & $(0.580)$ \\
\hline \multirow{2}{*}{$\ln R L / E$} & $-0.109^{* \star *}$ & 0.017 \\
\hline & $(0.042)$ & $(0.044)$ \\
\hline \multirow{2}{*}{$\ln W$} & $0.357^{* * *}$ & 0.010 \\
\hline & $(0.116)$ & $(0.116)$ \\
\hline \multirow{2}{*}{$\ln U N$} & $2.149^{* * *}$ & $2.896^{* * *}$ \\
\hline & $(0.398)$ & $(0.812)$ \\
\hline \multirow{2}{*}{$\ln S T U$} & 0.228 & 0.247 \\
\hline & $(0.192)$ & $(0.394)$ \\
\hline \multirow{2}{*}{$\ln C T$} & $-0.149^{\star * *}$ & $-0.230^{\star * *}$ \\
\hline & $(0.045)$ & $(0.046)$ \\
\hline \multirow{2}{*}{$\mathrm{W}^{*} \ln R L P$} & $0.707^{*}$ & \\
\hline & $(0.425)$ & \\
\hline rho & 0.185 & \\
\hline$R^{2}$ & 0.784 & \\
\hline $\log L$ & 23.068 & \\
\hline \multirow{2}{*}{ Sigma² } & $0.052^{* \star *}$ & \\
\hline & $(0.004)$ & \\
\hline Observed value & 372 & \\
\hline
\end{tabular}

a Note: The standard error term of the regression coefficient is in parentheses; $* * *, * *$ and * indicate that the significance level is less than $1 \%$, less than $5 \%$, and less than $10 \%$,

\section{CONCLUSIONS AND POLICY IMPLICATIONS}

\subsection{Conclusions}

This article uses panel data samples from 31 provincial administrative regions in Chinese mainland from 2007 to 2019 to explore the effect of volatility in the sale price of commercial housing on the total foreign direct investment in local and neighboring regions. Through the research results, it is found that the effect of rising local housing price on the total amount of local foreign direct investment is not significant, but the spatial spillover effect of rising local housing price on the total amount of foreign direct investment in neighboring regions is significantly positive. Moreover, the local region can further increase the enthusiasm of the entry of foreign capital by increasing the gross domestic product, expanding the total labor supply, and accelerating the level of urbanization development.

\subsection{Policy Implications}

Based on the above conclusions, this article proposes the following policy suggestions:

The first is to continue to maintain the financial support policy for foreign direct investment. Through the research results, it is found that rising local housing price will to a certain extent lead to the relocation of local foreign capital to neighboring regions, which may be caused by operating costs caused by housing costs. At this time, in the process of rising housing price, commercial housing transaction participants will often pay more taxes, which will increase government revenue. From the perspective of reducing the operating costs of enterprises, the local government can continue to maintain financial support policies for foreign-funded enterprises and reduce the actual operating costs of enterprises through transfer payment. 
The second is that maintaining a moderate economic growth rate is conducive to attracting the entry of foreign capital. Foreign capital entering the local market is often to pursue a larger sales market or to pursue richer and cheaper input of factor resources. Therefore, maintaining a moderate economic growth rate and allowing foreign enterprises to have expectations for the level of demand for entering the local market can yet be regarded as good strategies to promote the entry of foreign capital. This is an important reason why foreign investors have long been keen to invest in the Chinese market.

The third is to be on guard against the adverse impact of the slowdown in population growth on the entry of foreign capital. From the statistics published in several Chinese census reports, it can be found that the growth rate of China's total population has dropped significantly. From an average annual growth rate of $1.48 \%$ from 1982 to 1990 to an average annual growth rate of $0.53 \%$ from 2010 to 2020 , the slowdown in population growth will adversely affect foreign direct investment in China. In order to alleviate the impact of the gradual disappearance of the demographic dividend, it will be an important direction to seek alternatives to human input through the application of industrial robots and artificial intelligence.

The fourth is that accelerating the level of urbanization development is conducive to attracting the entry of foreign capital. It is also found through the research results that the increase in the level of urbanization will help expand the capacity of the local market and increase the local attractiveness of foreign direct investment. In the current process of urbanization, problems such as lagging urban management, widening income gaps, and insufficient public services are becoming increasingly prominent, all of which need to be further improved and perfected.

\section{AUTHORS' CONTRIBUTIONS}

Likui Lin is responsible for paper design and wrote the paper, Xiumei Li analysed data, Danqi Li wrote the manuscript and contributed to revising and editing.

\section{REFERENCES}

[1] Zezza, G. U.S. Growth, the housing market and the distribution of income $[\mathrm{J}]$. Journal of Post Keynesian Economics, 2008, 30(3): 375401.
[2] Rabe, B., M. Taylor. Differences in opportunities? Wage, unemployment and house-price effects on migration [J]. Oxford Bulletin of Economics \& Statistics, 2012, 74(6): 831-855.

[3] Zhou, Q., Q. Shao, X. Zhang, J. Chen. Do housing prices promote total factor productivity? Evidence from spatial panel data models in explaining the mediating role of population density [J]. Land Use Policy, 2021, 91: 1-15.

[4] Chaney, T., D. Sraer, D. Thesmar. The collateral channel: How real estate shocks affect corporate investment [J]. American Economic Review, 2012, 102(6): 2381-2409.

[5] Geary, R. C. The Contiguity Ratio and Statistical Mapping [J]. Incorporated Statistician, 1954, 5(3):115-146.

[6] Anselin, L. Local Indicators of Spatial Association-LISA [J]. Geographical Analysis, 1995, 27(2): 93-115.

[7] Lee, L., J. Yu. Estimation of Spatial Autoregressive Panel Data Models with Fixed Effects [J]. Journal of Econometrics, 2010, 154(2): 165-185.

[8] Anselin, L. Spatial Econometrics: Methods and Models [M]. The Netherlands: Kluwer Academic Publishers, 1988. 